\title{
Evaluation of life satisfaction of elderly people according to different life styles
}

\author{
Yaşlılarda farklı yaşam biçimlerine göre yaşam doyumlarının \\ değerlendirilmesi
}

Hatice Nilden ARSLAN ${ }^{1}$, Özlem TERZI ${ }^{2}$, Şennur DABAK ${ }^{2}$, Yıldız PEKŞEN ${ }^{2}$

\begin{abstract}
This study aimed to compare the life satisfaction levels of older people living in different environments and to investigate the effects of some socio-demographic attributes on their life satisfaction levels The study was planned as a descriptively-designed investigation. Considering the different living environments of the elderly, the study was performed in 3 groups of elderly as those staying at nursing home, elderly receiving home care, and living with their families. The survey form and Life Satisfaction Scale questioning the socio-demographic attributes were applied by the researchers during the face to face interviews. Upon evaluation of the groups with respect to their life satisfaction, it was found that the life satisfaction scores of the older people were

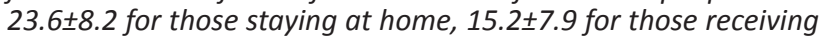
home care, and $12.3 \pm 5.7$ for those staying at nursing home. Life satisfaction score of older people staying at home was statistically significant higher than those receiving homecare, and residing in nursing homes $(p<0.001)$. Furthermore, when the older people were compared with regards to gender, marital status, educational status, desire to have a child, and need for psychological support, the life satisfaction scale scores of the old people living at home were found to be statistically significantly higher when compared to others $(p<0.05)$. Based on the results of our study, it is necessary for the older people to sustain their lives in their own homes or family environments in order to increase their life satisfaction levels. When they are in need of care, based on recommendations it is important to provide, and popularize care models which do not require them to leave their living environments and ensure maintenance of their active lives.
\end{abstract}

Keywords: Elderly, life satisfaction, life environment, nursing home öz

Bu çalışmada farklı ortamlarda yaşayan yaşlıların, yaşam doyumlarının karşılaștırılması ve bazı sosyodemografik özelliklerinin yaşam doyumlarına etkisinin belirlenmesi amaçlanmıştır. Çalışma tanımlayıcı araştırma olarak planlandı. Yaşlıların farklı yaşam ortamları dikkate alınarak huzurevinde kalan yaşlılar, evinde bakım hizmeti alan yaşlılar ve ailesiyle birlikte yaşayan yaşlılar olmak üzere üç grupta yapılması planlandı. Sosyodemografik özellikleri sorgulayan anket formu ve Yaşam Doyumu Ölçeği yüz yüze görüşme yöntemi ile araştırmacılar tarafından uygulandı. Gruplar yaşam doyumu açısından değerlendirildiğinde, evde kalan yaşlılarda yaşam doyumu puanı $23,6 \pm 8,2$, hizmet alanlarda $15,2 \pm 7,9$, huzurevinde kalanlarda ise $12,3 \pm 5,7$ olarak bulundu. Evde kalan yaşlılarda yaşam doyumu, hizmet alanlardan ve huzurevinde kalanlardan istatistiksel olarak anlamlı düzeyde daha yüksekti $(p<0,001)$. Ayrıca yaşlılar cinsiyet, medeni durum, eğitim durumu, çocuk sahibi olma, psikolojik destek gereksinimi açısından karşılaștırıldığında, evde kalan yaşlıların yaşam doyum ölçeğinden aldıkları puan diğerlerine göre istatistiksel olarak anlamlı düzeyde bulundu $(p<0,05)$. Calıșmamızdan elde edilen sonuçlara göre, yaşlıların yaşam doyumlarını arttırabilmek için yaşamlarının geri kalan sürecini kendi ev veya aile ortamında sürdürmesi sağlanmalıdır. Bakım gereksinimine gereksinimleri olduğunda, kendi yaşam ortamlarından ayırmadan, aktif yaşamlarını sürdürmelerini sağlayacak hizmet modellerinin yaygınlaştırılması konusunda çalışmalara ağırlık verilmesi önerilmektedir.

Anahtar kelimeler: Yaşlı, yaşam doyumu, yaşam ortamı, huzur evi

\section{Giriş}

Yaşlanma fiziksel, ruhsal ve sosyal yönden bireyde gerilemeye neden olan doğal bir süreçtir. Dünya Sağlık Örgütü (DSÖ) tarafından yapılan tanımlamada kronolojik yaş dikkate alınmakta ve yaşlılık dönemi "65 yaş ve üzeri" olarak kabul edilmektedir. Ancak farklı yaş kriterleri de kullanılmaktadır. Örneğin, Birleşmiş Milletler yaşlılar üzerine yapılan değerlendirmelerde 60 yaş ve üzerini dikkate almaktadır. Yaşlılık dönemi sınıflaması ise 65-74 yaş arası "genç yaşlı", 75-84 yaş arası "orta yaşı" ve 85 yaş üzeri ise "ileri yaşlı (ihti-

Received: 13.06 .2016

Accepted: 01.08.2016

${ }^{1}$ Directorate of Public Health

${ }^{2}$ Ondokuz Mayis University, Faculty of Medicine, Department of Public Health

Yazışma adresi: Özlem Terzi, Ondokuz Mayis University, Faculty of Medicine, Department of Public Health, Samsun

e-mail: ozlem.terzi@omu.edu.tr 
yar)" olarak yapılmıştır. Son zamanlarda DSÖ’nün çalışmalarında 60 yaş ve üzerinin yaşlı olarak kabul edildiği görülmektedir ${ }^{1,2}$.

2015 yılında dünya nüfusunun \%8,5'ini yaşlı nüfus oluşturduğu belirtilmiştir. Gelişmiş ülkelerde bu oran çok daha yüksek düzeydedir. Örneğin, Japonya'da nüfusun \%26,6'sını yaşlılar oluştururken, Almanya'da bu oranın \%21,5 olduğu gösterilmiştir. Ülkemizde ise 2015 yılında \%8,2 olan bu oranın 2050 yılında \%20,8'e çıkması beklenmektedir ${ }^{3}$.

Tüm dünyada yaşam süresinin uzamasıyla birlikte, yaşlı sağlığına daha çok önem verilmeye başlanmış ve bu alanda yeni kavramlar geliştirilmiştir. Bu kavramlardan biri olan başarılı yaşlanma süreci hem sağlık yönünden hem de psikolojik ve sosyal yönden iyilik halini içermektedir. Yapılan çalışmalarda yaşam doyumu düzeyi psikolojik olarak iyi olma hâlini göstermek amacıyla yaygın olarak kullanılmaktadır ${ }^{4}$. Yaşam doyumu ruh sağığını etkileyen önemli bir etken olup, mutluluk, moral gibi farklı açılardan iyi olma hâlinin göstergesidir. Yaşam doyum düzeyi yükseldikçe günlük hayatta olumlu duygular olumsuz duygulara egemen olmaktadır ${ }^{5}$. Yaşlılık döneminde ruhsal sorunlar oldukça sık yaşandığı için bu dönemdeki yaşam doyumu üzerinde önemle durulması gereklidir 6 . Yaşlıların yaşam doyumları yalnızca nasıl yaşlandıkları ile ilgili olmayıp, yaşadıkları çevreye nasıl uyum sağladıklarıyla da ilgilidir Çünkü bireylerin toplumsal ilişkileri, yaşam biçimi, yaşam biçimine uyum sağlama düzeyi ve içinde bulundukları koşulları kabullenmeleri de yaşam doyumunu etkiler ${ }^{7,8}$.

Yaşılık döneminde kronik hastalıkların ortaya çıkması, fiziksel kayıpların artması, emeklilikle birlikte toplumsal rollerin değişmesi ve ekonomik kayıplar sonucu çeşitli psikososyal sorunlar yaşanmaktadır. Ayrıca evde bakımına yardımcı olan kadınların iş yaşamına girmesi ve büyük ailelerin küçülerek çekirdek aileye dönüşmesiyle de yaşlıların aile içinde barınmaları konusunda sıkıntılar yaşanmaktadır. Bu sorunun çözümüne yönelik olarak toplum içinde farklı alternatifler aranmış; yaşlı köyleri, yaşlı apartmanları, bakım evleri ve huzur evleri gibi farklı bakım modelleri geliştirilmiştir ${ }^{9-11}$.
Bu çalışmada Samsun il merkezinde, farklı ortamlarda yaşayan yaşılırın, yaşam doyumlarının karşılaştırılması ve bazı sosyodemografik özelliklerinin yaşam doyumlarına etkisinin belirlenmesi amaçlanmıştır.

\section{GEREÇ ve YÖNTEM}

Tanımlayıcı tipteki bu araştırmanın yaşlıların farklı yaşam ortamları dikkate alınarak huzurevinde kalan yaşlılar, evinde bakım hizmeti alan yaşlılar ve ailesiyle birlikte yaşayan yaşlılar olmak üzere üç grupta yapılması planlandı. Bu amaçla Samsun Büyükşehir Belediyesi Huzurevinde kalan yaşıllar, Samsun Büyükşehir Belediyesi "Yaşadığı Yerde Yaşlıya Bakım Hizmetleri Merkezi"nden hizmet alan yaşlılar ve bu bölgelere yakın bir aile sağlığı merkezine kayıtlı olup, ailesiyle yaşayan yaşılıar çalışmaya dâhil edildi. Yaşadığı Yerde Yaşlıya Bakım Hizmetleri Merkezi, Samsun Büyükşehir Belediyesi sınırları içinde ikamet eden, eşiyle veya yalnız yaşayan, 60 yaş üzerinde, asgari ücretin altında gelire sahip olan yaşlılara hizmet vermektedir. Merkez aracılığıyla tamamen ücretsiz olarak, psikolojik destek hizmetleri, genel sağlık hizmetleri, temizlik hizmetleri, yemek hizmetleri sağlanmaktadır ${ }^{12}$.

Huzurevinin kapasitesi 60 kişi olduğu için diğer iki gruba dâhil edilecek yaşı ıayısının da 60 olmasına karar verildi ve örnek büyüklüğü 180 olarak belirlendi. Algısal sorunları nedeniyle iletişim kurulmakta güçlük çekilenler, ileri derece işitme özürlüler, demans tanısı olanlar ve araştırmaya katılmak istemeyen yaşılıar çıkarıldığında, huzurevinde 38 yaşlıya ulaşılabildi. Böylece toplam 158 yaşlıyla \%87,7 oranında çalışmaya katılım sağlandı. Çalışma sonucu elde edilen yaşam doyum puan ortalama ve standart sapmaları dikkate alınarak yapılan güç analizinde MINITAB $13.0 \mathrm{~V}$ istatistik paket programı kullanıldı ve çalışmanın gücü 0,80 olarak bulundu.

Araştırmada Diener ve ark. ${ }^{13}$ tarafından 1985 yılında, bireylerin yaşamlarından aldıkları doyumu belirlemek amacı ile geliştirilen Yaşam Doyumu Ölçeği (The Satisfaction with Life Scale-SWLS) kullanıldı. Ölçek, likert tarzı 7 dereceli (1: Kesinlikle katılmıyorum - 7: Kesinlikle katılıyorum) beş maddeden oluşmaktadır. 
Yaşam Doyumu Ölçeğinden alınabilecek en yüksek puan 35, en düşük puan ise 5 olup, ölçekten alınan yüksek puan, yaşam doyumunun yüksekliğini göstermektedir $^{14}$. Ölçek, Türkiye'deki popülasyona Yetim tarafından uygulanmıştır ${ }^{15}$.

Etik Konular: Araştırma öncesinde çalışmanın yapılacağı kurumlardan yasal izinler alındı. Yaşlılardan sözlü onam alındıktan sonra sosyodemografik özellikleri sorgulayan anket formu ve Yaşam Doyumu Ölçeği yüz yüze görüşme yöntemi ile araştırmacılar tarafından uygulandı.

Verilerin istatistiksel değerlendirmesinde SPSS versiyon 15.0 bilgisayar paket programı kullanıldı. Tanımlayıcı istatistikler ortanca (minimum-maksimum) veya ortalama \pm standart sapma, sayı, yüzde olarak verildi. Grupların karşılaştırılmasında ki-kare testi, Kruskall Wallis Varyans Analizi ve Tek Yönlü Varyans Analizi (Post Hoc: Tukey Testi) yapıldı ve istatistiksel anlamlılık düzeyi $p<0,05$ olarak kabul edildi.

\section{BULGULAR}

Araştırmada hizmet alan yaşlıların yaş ortalaması $74,8 \pm 8,1$ yıl, huzurevinde kalanların $69,1 \pm 8,5$ yıl ve evde yaşayanların $68,2 \pm 5,9$ yıl olarak saptandı. Hizmet alanların yaş ortalaması diğer iki gruptan istatistiksel olarak anlamlı oranda yüksekti (p:0,001). Yaşlıların sosyodemografik özellikleri Tablo 1'de verildi.
Gruplar sosyodemografik özellikler bakımından karşılaştırıldığında cinsiyet, medeni durum, gelir durumu ve çocuk sahibi olma durumları açısından gruplar arasında istatistiksel olarak anlamlı düzeyde fark var$d_{\imath}(p<0,05)$ (Tablo 1$)$.

Huzurevinde kalanların \%31,6'sı, hizmet alanların $\% 11,7$ 'si, evde kalan yaşlıların \%5,0'i çocuk sahibi değildi ve huzurevinde kalanlarda çocuk sahibi olmayanların oranı diğer gruplardan istatistiksel olarak anlamlı düzeyde yüksekti $\left(X^{2}: 14.1, p<0,05\right)$. Birlikte yaşadıkları kişiler bakımından değerlendirildiğinde evde kalan yaşılırın 9'u $(\% 15,0)$ yalnız, 43'ü $(\% 71,7)$ eşiyle, 8'i $(\% 13,3)$ çocuklarıyla; hizmet alanların 27'si $(\% 45,0)$ yalnız, 23'ü $(\% 38,3)$ eşiyle, 7'si $(\% 11,7)$ çocuklarıyla, 3 'ü $(\% 5,0)$ ise bakıcı ile birlikte yaşıyordu. Psikolojik destek gereksinimleri sorulduğunda evde kalan yaşlıların \%42'si, hizmet alanların \%73'ü, huzurevinde kalanların ise $\% 65$ 'i zaman zaman psikolojik desteğe gereksinim duyduklarını belirtmişlerdi. Evde kalan yaşlılarda psikolojik destek gereksinimi diğerlerinden anlamlı oranda düşüktü $\left(X^{2}: 8,3, p<0,05\right)$.

Gruplar yaşam doyumu açısından değerlendirildiğinde, evde kalan yaşlılarda yaşam doyumu puanı $23,6 \pm 8,2$, hizmet alanlarda 15,2 $\pm 7,9$, huzurevinde kalanlarda ise $12,3 \pm 5,7$ olarak bulundu. Evde kalanlarda yaşam doyumu, hizmet alanlardan ve huzurevinde kalanlardan istatistiksel olarak anlamlı düzeyde daha yüksekti $(p<0,001)$.

Tablo 1. Yaşlıların bazı sosyodemografik özelliklerinin karşılaştırılması.

\begin{tabular}{|c|c|c|c|c|c|c|}
\hline & & $\begin{array}{l}\text { Evde Yaşayan } \\
\qquad \begin{array}{c}(n=60) \\
\%\end{array}\end{array}$ & $\begin{array}{c}\text { Hizmet Alan } \\
\begin{array}{c}(n=60) \\
\%\end{array}\end{array}$ & $\begin{array}{c}\text { Huzurevinde Kalan } \\
\begin{array}{c}(\mathrm{n}=38) \\
\%\end{array}\end{array}$ & $x^{2}$ & $p$ \\
\hline \multirow[t]{3}{*}{ Cinsiyet } & Kadın & 46,7 & 70,0 & 18,4 & & \\
\hline & Erkek & 53,3 & 30,0 & 81,6 & 24,9 & $<0,001$ \\
\hline & Evli & 73,3 & 40,0 & 13,2 & & \\
\hline \multirow[t]{2}{*}{ Medeni durum } & Bekâr & 1,7 & 5,0 & 23,7 & 56,7 & $<0,001$ \\
\hline & Dul & 25,0 & 55,0 & 63,1 & & \\
\hline \multirow[t]{3}{*}{ Eğitim durumu } & Okuryazar değil & 25,0 & 50,0 & 39,5 & & \\
\hline & Okuryazar & 20,0 & 18,3 & 15,8 & 8,9 & 0,062 \\
\hline & İlkokul ve üzeri & 55,0 & 31,7 & 44,7 & & \\
\hline \multirow[t]{2}{*}{ Gelir durumu } & Geliri yeterli & 45,0 & 20,0 & 47,4 & 10,8 & 0,004 \\
\hline & Geliri yetersiz & 55,0 & 80,0 & 52,6 & & \\
\hline \multirow[t]{2}{*}{ Çocuk sahibi olma } & Var & 95,0 & 88,3 & 68,4 & 14,1 & $<0,001$ \\
\hline & Yok & 5,0 & 11,7 & 31,6 & & \\
\hline
\end{tabular}


Tablo 2. Araştırma Grubunda Yaşam Doyumu Ölçek Puanlarının Bazı Özelliklere Göre Dağılımı.

\begin{tabular}{|c|c|c|c|c|c|}
\hline & & $\begin{array}{c}\text { Evde Yaşayan } \\
\text { ort } \pm s s\end{array}$ & $\begin{array}{l}\text { Hizmet Alan } \\
\text { ort } \pm \text { ss }\end{array}$ & $\begin{array}{c}\text { Huzurevinde Kalan } \\
\text { ort } \pm \text { ss }\end{array}$ & $\mathbf{p}$ \\
\hline \multirow[t]{2}{*}{ Yaş } & Yaşlı & $23,7 \pm 8,3^{*}$ & $14,1 \pm 7,9$ & $11,6 \pm 5,3$ & $<0,001$ \\
\hline & İleri Yaşlı & $23,2 \pm 7,7^{*}$ & $16,0 \pm 7,9$ & $14,0 \pm 6,4$ & 0,021 \\
\hline \multirow[t]{2}{*}{ Cinsiyet } & Erkek & $24,2 \pm 8,3^{*}$ & $15,6 \pm 8,2$ & $12,9 \pm 6,2$ & $<0,001$ \\
\hline & Kadın & $23,0 \pm 8,2^{*}$ & $15,0 \pm 7,9$ & $10,0 \pm 0,0$ & $<0,001$ \\
\hline \multirow[t]{2}{*}{ Medeni Durumu } & Evli & $24,1 \pm 8,4^{*}$ & $16,4 \pm 8,1$ & $13,2 \pm 7,3$ & $<0,001$ \\
\hline & Eşi ölmüş & $22,4 \pm 7,8^{*}$ & $14,3 \pm 7,6$ & $11,3 \pm 4,9$ & 0,001 \\
\hline \multirow[t]{3}{*}{ Eğitim Durumu } & Okuryazar değil & $20,7 \pm 8,1^{*}$ & $15,8 \pm 7,8$ & $11,3 \pm 5,1$ & 0,008 \\
\hline & Okuryazar & $25,9 \pm 7,6^{*}$ & $14,7 \pm 7,0$ & $14,5 \pm 7,0$ & 0,002 \\
\hline & İlkokul ve üzeri & $24,2 \pm 8,3^{*}$ & $14,5 \pm 8,8$ & $12,5 \pm 5,9$ & $<0,001$ \\
\hline \multirow[t]{2}{*}{ Gelir Durumu } & Yeterli & $27,4 \pm 4,5$ & $21,6 \pm 9,0$ & $12,6 \pm 5,4^{*}$ & $<0,001$ \\
\hline & Yetersiz & $20,6 \pm 9,3 *$ & $13,6 \pm 6,8$ & $12,1 \pm 6,2$ & $<0,001$ \\
\hline \multirow[t]{2}{*}{ Çocuk Sahibi Olma Durumu } & Var & $23,7 \pm 8,1^{*}$ & $15,8 \pm 7,9$ & $14,2 \pm 7,7$ & $<0,001$ \\
\hline & Yok & $23,3 \pm 11,5^{*}$ & $10,7 \pm 6,7$ & $11,5 \pm 4,4$ & $<0,001$ \\
\hline \multirow[t]{2}{*}{ Psikolojik Destek Gereksinimi } & Var & $21,9 \pm 8,1^{*}$ & $14,8 \pm 8,1$ & $11,7 \pm 5,2$ & $<0,001$ \\
\hline & Yok & $25,2 \pm 8,1^{*}$ & $16,3 \pm 7,5$ & $13,2 \pm 6,4$ & $<0,001$ \\
\hline
\end{tabular}

*Farkı yaratan alt grup

Araştırma grubundaki kişiler "yaşlı" ve "ileri yaşlı" olarak iki gruba ayrıldı. Altmış-yetmiş dört yaşında olanlar "yaşı", 75 yaş ve üzerindekiler ise "ileri yaşı" kabul edilerek yaşam doyum puanları açısından karşılaştırıldığında her iki grupta da evde kalanların yaşam doyumunun istatistiksel olarak anlamlı düzeyde yüksek olduğu görüldü $(p<0,05)$.

Yaşam doyumu ölçeğinden alınan puanlar cinsiyet, medeni durum, eğitim durumu, çocuk sahibi olma, psikolojik destek gereksinimi alt gruplarında karşılaştırıldığında evde yaşayanların yaşam doyum puanı tüm alt gruplarda diğerlerine göre yüksekti ve bu yükseklik istatistiksel olarak anlamlı bulundu $(p<0,05)$. Ancak gelir durumu açısından değerlendirildiğinde geliri "yeterli" olup, evde yaşayanlar ile bakım hizmeti alanlarda yaşam doyum puanı huzurevinde kalanlardan istatistiksel olarak anlamlı düzeyde yüksekti (Tablo 2 ).

\section{TARTIŞMA}

Son yıllarda önem kazanan bir kavram olan yaşam doyumu üzerine yapılan çalışmaların çoğu yaşlı bireyler üzerinde yapılmıştır. Yaşam doyumu ve yaş ilişkisinin araştırıldığı pek çok çalışmada yaş arttıkça yaşam doyumunun azaldığı gösterilmiştir ${ }^{16-18}$. Ancak Suh ve ark.'nın ${ }^{19}$ çalışmasında, yaşın yaşam doyumu üzerine etkili olmadığı belirtilmiştir. Çalışmamızda da, huzurevinde kalanların yaş ortalaması daha yüksek ve yaşam doyum puanları daha düşüktü. Ancak yaşlarına göre oluşturulan ileri yaşlı ve yaşlı grupları arasında bakıldığında yaşam doyum puan ortalamaları arasında anlamlı farklılık yoktu. Evde yaşayanların her iki yaş grubunda da yaşam doyum puanları diğer yaşam ortamlarından anlamlı düzeyde yüksekti. Bu durumda yaşılır için yaşların değil hangi ortamda yaşadıklarının yaşam doyumu için daha önemli olduğu kanaatine varılmıştır.

Cinsiyet açısından yapılan çalışmalar incelendiğinde, Brog ve ark.'nın ${ }^{17}$ çalışmasında, evde yaşayan erkeklerin kadınlara göre yaşam doyumlarının daha yüksek olduğu görülmüştür. Huzurevinde yapılan bir çalışmada da, yine erkeklerde anlamlı düzeyde yüksek bulunmuştur ${ }^{18}$. Ancak Shin ve ark.'nın ${ }^{20}$ yalnız yaşayan ve evde aileleriyle birlikte yaşayan yaşlılar üzerine yaptıkları çalışmada, cinsiyetler arasında fark olmadığı belirlenmiştir. Shin ve ark.'nın ${ }^{20}$ çalışmasının sonucuna benzer şekilde bu çalışmada da aynı yaşam ortamlarında, cinsiyetler arası alınan puanlar arasında anlamlı farklılık yoktu. Bununla beraber çalışmamızda, evde yaşayan erkeklerin ve kadınların diğer gruplardaki hemcinslerine göre daha yüksek yaşam doyumuna sahip oldukları görüldü. Özer ve ark.'nın ${ }^{21}$ çalışmasında da, benzer şekilde aile ortamında yaşayan erkek ve kadınlarda yaşam doyumu, huzurevinde 
yaşayanlara göre daha yüksek bulunmuştur. Hangi cinsiyette olursa olsun yaşlıların kendilerine ait bir ortamda eşleriyle ve çocuklarıyla yaşamlarını devam ettirmeleri, olasılıkla onları daha mutlu kılmakta ve yaşamdan keyif almalarını sağlamaktadır.

Yaşam doyum puanı üzerine etkisi araştırılan bir diğer konu da eğitim düzeyidir. Ülkemizde yapılan bazı çalışmalarda, yaşlılarda eğitim düzeyi arttıkça yaşam doyumunun arttığı gösterilmiştir ${ }^{5,18,22}$. Bununla birlikte, eğitimin yaşlılarda yaşam doyumunu etkilemediğini gösteren çalışmalar da mevcuttur ${ }^{19,20}$. Bu çalışmada, yaşam doyum puanı, tüm eğitim düzeylerinde evde yaşayan yaşlılarda daha yüksek bulundu. Ancak aynı grup içinde değerlendirildiğinde, farklı eğitim düzeyleri arasında yaşam doyum puanları açısından anlamlı fark yoktu ve bu bulgular ışığında eğitim düzeyinin yaşam doyumuna doğrudan etkili olmadığı söylenebilir. Çalışmamızın bir kısıtlıı̆ğı olarak ilkokul ve üzeri eğitim düzeyindekiler, sayılarının az olması nedeniyle tek bir grup olarak değerlendirilmiştir. Olasılıkla lise ve üniversite mezunu yaşlılarda, kendi öz bakım ve sağlık gereksinimlerini daha iyi bilecekleri ve sahip oldukları olanakları daha iyi değerlendirebileceklerinden dolayı yaşam doyumu daha yüksek beklenebilir.

Yapılan çalışmalarda, gelir durumunun yaşam doyumunu etkilediği, geliri gereksinimini karşılayan yaşlılarda yaşam doyumunun daha yüksek olduğu bulunmuştur ${ }^{19,23}$. Bir başka çalışmada ise, yalnız yaşayanlar ile ailesiyle birlikte yaşayan yaşılıarda gelirleri arttıkça yaşam doyum puanlarının artmakta olduğu gösterilmiştir ${ }^{20}$. Çalışmamızda ise, geliri yetenler arasında değerlendirildiğinde huzurevinde kalanların puanı anlamlı derecede düşük bulundu. Bu durum yeterli gelirleri olduğu halde huzurevinde olmayı kabullenememelerinin göstergesi olabilir. Yine geliri yetmeyenler karşılaştırıldığında evde yaşayan yaşılıarın yaşam doyumunun diğer yaşlılardan anlamlı düzeyde daha yüksek olduğu bulundu. Bu durumda yetersiz gelire rağmen, evde aileleriyle birlikte yaşamanın yaşam doyumuna olumlu katkısı olduğu düşüncesine varıldı. Hizmet alan grupta ise geliri yetenlerin yaşam doyum puanlarının yetmeyenlere göre daha yüksek olduğu görülmektedir. Bu durum, yaşlıların dışarıdan çeşitli bakım hizmetlerini almakla birlikte, daha yüksek gelir düzeyine sahip olmanın gelecek için bir güvence olarak görülmesi ve gerektiğinde daha iyi tedavi veya bakım hizmetine ulaşabileceklerini düşünmelerinden kaynaklanıyor olabilir.

Genel olarak çocuklu yaşlıların psikolojik iyi oluşlarının ve yaşam doyumlarının daha yüksek olduğu çaIışmalarda gösterilmiştir ${ }^{24}$. Ancak çalışmamızda, beklenilenin aksine hizmet alan ve huzurevinde kalan çocuk sahibi yaşlıların yaşam doyum puanı düşük bulundu. Altay ve ark.'nın ${ }^{25}$ huzurevinde kalan yaşlılarla yaptıkları çalışmada, çocuk sahibi olmanın yaşam doyumunu etkilemediği görülmüştür. Her ne kadar çocuk sahibi olmak insanlar için yaşlılık döneminde bir güvence olarak algılansa da gerçekte çocukları ile birlikte yaşlıık sürecini geçiremeyen yaşııların olumsuz duygular içinde oldukları ve dolayısıyla yaşam doyumlarının düşük olduğu sonucuna varıldı.

Yalnızca ülkemizde değil farklı ülkeler ve kültürlerde de huzurevinde yaşayan yaşlılar kendilerini daha yalnız ve mutsuz hissetmektedirler. Bu alanda yapılan birçok çalışmada, huzurevleri veya benzer kurumsal yapılarda kalan yaşılıarın daha depresif oldukları ortaya konmaktadır ${ }^{26,27}$. Kerem ve ark.'nın ${ }^{28}$ çalışmasında da, huzurevinde kalan yaşlıların psikolojik yönden zorlandıkları görülmüştür. Uzun süreli izlem araştırmalarında ailesiyle birlikte yaşayan yaşlıların, tek başına veya huzurevinde yaşayanlardan psikolojik olarak çok daha iyi durumda oldukları gösterilmiştir ${ }^{29}$. Bir başka çalışmada ise, bağımsız yaşayan yaşlıların huzurevinde kalanlara göre psikolojik olarak daha iyi düzeyde oldukları belirtilmiştir ${ }^{19,30}$. Çalışmamızda ise, hizmet alan grupta yalnız yaşama oranının yüksek olması nedeniyle psikolojik desteğe diğer gruplardan daha fazla gereksinim duyulduğu ve buna bağlı olarak da yaşam doyum puanının evde kalan gruptan daha düşük olduğu sonucuna varıldı. Huzurevinde kalanlar ise yaşadıkları ortamda yalnız olmadıklarından daha az psikolojik destek ihtiyaç duymakla beraber yine de yaşam doyumları daha düşük düzeydedir.

Genel olarak değerlendirildiğinde huzurevinde kalan 
yaşlıların yaşam doyumları daha düşük düzeydedir. Örneğin Gueldner ve ark.'nın ${ }^{31}$ ve Brog ve ark.'nın ${ }^{17}$ yaptığı çalışmalarda, huzurevinde yaşayanların yaşam doyumu toplum içinde yaşayanlardan düşük olarak bildirilmiştir. Özer'in ${ }^{21}$ çalışmasında da, huzurevinde kalanların yaşam doyumu, aile ortamında yaşayan yaşlılardan düşük bulunmuştur. Shin ve ark.'nın ${ }^{20}$ çaIışmasında ise, aileleri ile kalanların yaşam doyumları yalnız yaşayan yaşlılara göre daha yüksek bulunmuştur. Çalışmamızda, yaşlılarda yaşam doyum puanı yaş, cinsiyet, medeni durum, eğitim ve gelir düzeyi, kronik hastalık varlığı ve çocuk sahibi olma durumları açısından irdelenmiş ve evde kalanlarda tüm incelenen durumlarda diğer yaşlılardan daha yüksek bulunmuştur. Yaşlılara bakım gereksinimlerini dolayı oluşturulan kurumsal bir hizmet olarak sunulan huzurevlerinin yaşılırın sağlık, barınma, yemek gibi her türlü temel gereksinimlerini karşılamasına ve sosyal olanaklar sunmasına rağmen, yaşlıların psikolojik olarak iyi olmasında, yaşamdan doyum almasında yeterince etkili olmadığı düşüncesindeyiz. Zaten son yıllarda ülkemizde kurum bakımı son seçenek olarak değerlendirilmeye ve yaşlı bireyin bakımının aile üyelerince üstlenilmesi devlet tarafından desteklenmeye başlamıştır ${ }^{11}$.

Her ne kadar kendi evlerinde yaşamlarını sürdürmekte olup, belediyeden gereksinimlerine yönelik çeşitli bakım hizmetleri alsalar da hizmet alan grubun yaşam doyum puanının düşük olması dikkat çekicidir. Yaşlıların bakım gereksinimlerinin karşılanmasında çocukların ve diğer aile bireylerinin aktif rol alması, yaşlılarla aralarında ilişkinin daha canlı ve sıcak olmasını sağlayacağı gibi yaşlılık sürecindeki psikolojik iyi olma hâlinin gerçekleşmesine de katkı sağlayacaktır.

Sonuç olarak, yaşlılık döneminde yaşanan en önemli sorunlardan birisi yaşlıların bakımıdır. Bu durumda yaşlıların öncelikle kendi evlerinde olabildiğince güvenli, bağımsız, rahat ve huzurlu bir şekilde yaşamaları en ideal bakım modelidir. Bakım gereksinimine gereksinimleri olduğu durumda, yaşlıları kendi ev veya aile ortamından ayırmadan, aktif yaşamlarını sürdürmelerini sağlayacak hizmet modellerinin yaygınlaştırılması konusunda çalışmalar sürdürülmelidir.
Yaşlının kendi evinde bakımı olanak dahilinde değilse, oluşturulacak huzurevleri gibi kurumsal çözümlerde de yaşlıların yalnızca temel gereksinimlerinin karşılanması değil, psikolojik olarak da desteklenmesi sağlanmalıdır.

\section{KAYNAKLAR}

1. WHO,The uses of epidemiology in the study of the elderly. Technical Reports Series 706, 1984, Geneva:8-9.

2. Bilir N, Erbaydar NP. Yaşlılık sorunları In: Güler Ç, Akın L. eds. Halk Sağ Iığı Temel Bilgiler 3. Baskı. Hacettepe Üniversitesi Yayınları 2015:1528-41.

3. http://www.tuik.gov.tr/PreHaberBultenleri.do?id=21520 Erişim tarihi: 25.05.2016

4. Görgün BA. Yaşııııta sosyalizasyon ve yaşam kalitesi. Yaşlı Sorunları Araştırma Dergisi 2008;1(2):86-97.

5. Özer M, Karabulut ÖÖ. Yaşlılarda yaşam doyumu. Turkish Journal of Geriatrics 2003;6(2):72-74.

6. Şener A. Yaşlılık, Yaşam doyumu ve Boş Zaman Faaliyetleri. http://www.sdergi.hacettepe.edu.tr/makaleler/yasamdoyumu.pdf Access date:05/25/2016

7. Chen C. Aging and Life Satisfaction. Social Indicators Research 2001;54:57-79.

http://dx.doi.org/10.1023/A:1007260728792

8. Kudo H, Izumo Y, Kodamo, et al. Life Satisfaction in Older People. Japan Geriatrics Society 2007;7:15-20.

http://dx.doi.org/10.1111/j.1447-0594.2007.00362.x

9. Sökmen DÇ. Huzurevinde Kalan Yaşlıların Huzurevindeki Yaşamlarına îlişkin Algıları. Marmara Üniversitesi Eğitim Bilimleri Enstitüsü, Yüksek Lisans Tezi, İstanbul. 2008

10. Dahlan A, Nicol M, Maciver D. Elements of life satisfaction amongst elderly people living in institutions in Malaysia: A mixed methodology approach. Hong Kong Journal of Occupational Therapy 2010;20(2):71-9.

http://dx.doi.org/10.1016/S1569-1861(11)70006-7

11. Baykan Z. Yaşlı Sağlığı In: Öztürk Y, Günay O. eds. Halk Sağıı̆ı Genel Bilgiler 1. Baskı. Erciyes Üniversitesi yayınları, 2010:769-89.

12. http://www.samsun.bel.tr/belediye-detay.asp?belediye= 673-yaslilara-bakim-hizmeti\# Access date:05/25/2016

13. Diener E, Emmons RA, Larsen RJ. et al. The satisfaction with life scale. Journal of Personality Assessment 1985;49:71-5. http://dx.doi.org/10.1207/s15327752jpa4901_13

14. Pavot W, Diener E. The Satisfaction With Life Scale and the emerging construct of life satisfaction. Journal of Positive Psychology 2008;3:137-52. http://dx.doi.org/10.1080/17439760701756946

15. Yetim U. Life satisfaction: A study based on the organization of personal projects. Soc Indic Res 1993;29:277-89. http://dx.doi.org/10.1007/BF01079516

16. Dönmez MM. Meslek Lisesi Öğrencilerinin Atılganlık Düzeylerine Göre Yaşam Doyumu ve Duyguları İfade Etme Eğilimlerinin Karşılaştırılması. Ankara Üniversitesi Eğitim Bilimleri Enstitüsü, Yüksek Lisans Tezi, Ankara. 2007

17. Borg C, Hallberg IR, Blomqvist K. Life satisfaction among older people $(65+)$ with reduced self-care capacity: the relationship to social, health and financial aspects. Journal of Clinical Nursing 2006;15(5):607-18. http://dx.doi.org/10.1111/j.1365-2702.2006.01375.x 
18. Bakış E. Huzurevlerinde yaşayan yaşlı bireylerde öz bakım gücünün yaşam doyumlarına etkilerinin incelenmesi, Marmara Üniversitesi, Sağlık Bilimleri Enstitüsü Yüksek Lisans Tezi, İstanbul, 2002

19. Suh S, Choi H, Lee C, et al. Association between knowledge and attitude about aging and life satisfaction among older Koreans. Asian Nursing Research 2012;6(3):96-101. http://dx.doi.org/10.1016/j.anr.2012.07.002

20. Shin SH, Sok SR. A comparison of the factors influencing life satisfaction between Korean older people living with family and living alone. International Nursing Review 2012;59(2):252-8. http://dx.doi.org/10.1111/j.1466-7657.2011.00946.x

21. Özer M. A study on the life satisfaction of elderly individuals living in family environment and nursing homes. Turkish Journal of Geriatrics 2004;7(1):33-6.

22. Subaşı $F$, Hayran O. Evaluation of life satisfaction index of the elderly people living in nursing homes. Archives of Gerontology and Geriatrics 2005;41(1):23-9. http://dx.doi.org/10.1016/j.archger.2004.10.005

23. Berg Al, Hassing LB, McClearn GE, et al. What matters for life satisfaction in the oldest-old?. Aging and Mental Health 2006;10(3):257-64. http://dx.doi.org/10.1080/13607860500409435

24. Zhang W, Liu G. Childlessness, psychological well-being, and life satisfaction among the elderly in China. Journal of Crosscultural Gerontology 2007;22(2):185-203. http://dx.doi.org/10.1007/s10823-007-9037-3
25. Altay B, Avcı IA. Huzurevinde yasayan yaslılarda özbakım gücü ve yasam doyumu arasındaki ilşki. Dicle Tıp dergisi 2009;36(4):275-282.

26. Kim O, Byeon YS, Kim JH, et al. Loneliness, depression and health status of the institutionalized elderly in Korea and Japan. Asian Nursing Research 2009;3(2):63-70. http://dx.doi.org/10.1016/S1976-1317(09)60017-7

27. Choi NG, Ransom S, Wyllie, RJ. Depression in older nursing home residents: The influence of nursing home environmental stressors, coping, and acceptance of group and individual therapy. Aging and Mental Health 2008;12(5):536-47. http://dx.doi.org/10.1080/13607860802343001

28. Kerem M, Meriç A, Kırdı N ve ark. Ev ortamında ve huzurevinde yaşayan yaşlıların değişik yönlerden değerlendirilmesi. Geriatri 2001;4(3):106-112.

29. Wu Z, Schimmele CM. Living Arrangements and Psychological Disposition of the Oldest Old Population in China. In: Y Zeng, DL. Poston, JD Ashbaugh et al,eds. Healthy Longevity in China. Netherlands: Springer Press 2008: 197-213. http://dx.doi.org/10.1007/978-1-4020-6752-5_12

30. Davis NC, Friedrich D. Knowledge of aging and life satisfaction among older adults. The International Journal of Aging and Human Development 2004;59(1):43-61. http://dx.doi.org/10.2190/U9WD-M79K-9HB8-G9JY

31. Gueldner SH, Loeb S, Morris D, et al. A comparison of life satisfaction and mood in nursing home residents and community-dwelling elders. Archives of Psychiatric Nursing 2001;15(5):232-240. http://dx.doi.org/10.1053/apnu.2001.27020 